\title{
Green Roofs: effects of hydrogel on hydrological and ecological behavior
}

\author{
S.S. Cipolla ${ }^{1}$, L. Ferroni2 ${ }^{*}$, M. Maglionico ${ }^{3}$, and M. Speranza ${ }^{2}$ \\ 1 Interdepartmental Centre for Industrial Research-Building and Construction, University of Bologna, Bologna, \\ Italy; ${ }^{2}$ Department of Agricultural Sciences, University of Bologna, Bologna, Italy; ${ }^{3}$ Department of Civil, Chemical, \\ Environmental, and Materials Engineering, University of Bologna, Bologna, Italy.
}

\begin{abstract}
Green roofs are frequently exposed to extremely hard condition, in particular in Mediterranean area due to the shallow depth and low water holding capacity of the substrate, and to the custom of reducing maintenance costs, avoiding irrigation. This study presents the effects of a hydrogel polymer on the hydrological behavior and on growth of Sedum hispanicum L. and Bromus erectus Huds. Plants were grown in six test beds containing $10 \mathrm{~cm}$ of substrate mixed with three concentration of hydrolgel: $0 \%$ $\mathrm{w} / \mathrm{w}$ ( 2 modules with substrate itself), $0.3 \% \mathrm{w} / \mathrm{w}(2$ modules) and $0.6 \% \mathrm{w} / \mathrm{w}(2$ modules). Weather data were collected continuously, while runoff was measured for three events. The water losses, due to evapotranspiration (ET, in $\mathrm{mm} / \mathrm{day}$ ), were evaluated by measuring the difference between the daily changes in weight of the boxes. Furthermore, two plant traits (leaf dry matter content - LDMC and relative water content - RWC) were used to evaluate the ecological behavior of the species. RWC was measured during the runoff measurement; LDMC was measured at the beginning of the experiments and after 3 months. Preliminary results show that the presence of hydrogel strongly influence the retention performance of green roofs, in fact the higher the hydrogel concentration the higher the retention. Hydrogel increases the substrate water content at saturation, as well as the water available for vegetation and consequently the greater the hydrogel concentration and the greater the daily losses for ET. Regarding the ecological performance, the preliminary results show that the presence of hydrogel does not influence the species RWC, moreover the LDMC values show a decreasing after 3 months especially for Bromus. LDMC has been shown to correlate negatively with potential relative growth rate; the presence of hydrogel then helps the vegetation growth.
\end{abstract}

Keywords: green roofs, hydrogel, retention

\section{INTRODUCTION}

Green roofs (GRs) are multi-layered systems containing mainly plants and substrate. The key characteristic of a GR is its multi-functionality, or rather, its ability to perform multiple environmental, ecological, and social functions, which allow producing a livable urban environment (Cipolla et al., 2016a). The ability in reducing the volume of storm water runoff depends by both the state of the vegetation and the ability of GR technology to retain water runoff. Recent studies suggested the use of hydrogel polymers to enhance the water holding capacity and the plant available water of green roof substrates (Farrell et al., 2013). Hydrogel is a polymer, which contains water-insoluble highly cross-linked polyacrylamides, and it can absorb water up to 400 times its own weight when saturated (Savi et al., 2014). Young et al. (2015) demonstrated that hydrogel increases the tolerance of perennial green roof plants of drought. This is possible thanks to the greater amount of rainfall/irrigation water trapped by hydrogel particles and available during dry periods for vegetation growth. However, little attention has been paid to the effect of hydrogel to the hydrological behavior of a GR. From an hydrological point of view the retention is one of the most investigated parameter on GRs research (Cipolla et al., 2016b). The average retention, which appeared to

\footnotetext{
*E-mail: lucia.ferroni@unibo.it
} 
range between $11 \%$ and $74 \%$, depends of a number of parameters such as the climate, the vegetation cover, the substrate depth and composition (Cipolla et al., 2016). Green roofs are commonly planted with succulents such as Sedum spp. However, there is a movement to incorporate other plant life-forms, such as grasses, to increase functional diversity and to improved the performance in terms of retention of the green roofs. To streamline the process of plant selection for green roofs, ecologists have turned to plant traits to determine which general plant characteristics are related to survival, and growth (Farrell et al., 2013). Between plat traits, Leaf Dry Matter Content (LDMC) is considered as a "hard traits" and is usually negatively associated with growth rates (Gross et al., 2007). Relative water content (RWC) is probably the most appropriate measure of plant water status, RWC provides a measurement of the 'water deficit' of the leaf, and may indicate a degree of stress expressed under drought and heat stress. A species with the ability to minimize stress by maintaining turgid leaves in stressed environments will have physiological advantages. To the best of our knowledge, a comparative study of the presence of hydrogel in the substrate has never been combined with a monitoring activity on the hydrological and ecological behavior of green roofs. Consequently, the aim of this study is those of evaluating the effects of hydrogel in terms of retention, evaporation, vegetation growth and water stored.

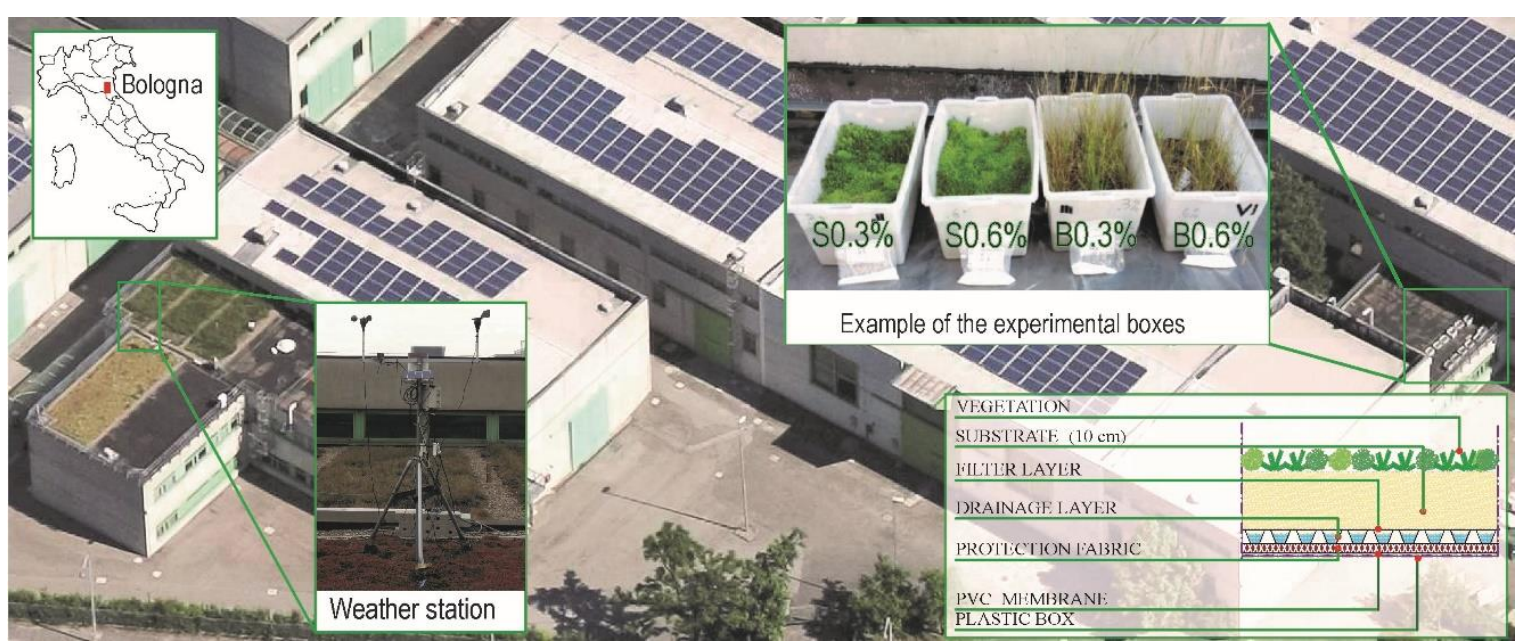

Figure 1. Aerial view of the experimental site showing: the location of the experimental test boxes, the position of the weather station and the stratigraphy of the green roof.

\section{MATERIALS AND METHODS}

The experimental green roofs test beds (Fig. 1) were located at the Engineering Campus in Bologna, Italy. The test beds consist in plastic boxes $(40 * 60 * 50 \mathrm{~cm})$ that host an extensive green roof package, with $10 \mathrm{~cm}$ substrate depth, provided by Harpo Spa. The water absorbent polymer hydrogel used in this project is "cross linked polyacrilic acid-potassium salt", STOCKSORB 660 medium (www.creasorb.com). Based on plant covering, experimental boxes are divided into two main categories: 1) Sedum hispanicum L., and 2) Bromus erectus Huds. Within each category, three modules contain substrate mixed with hydrogel in the following three concentration: a) $0 \% \mathrm{w} / \mathrm{w}$ (substrate itself), b) $0.3 \% \mathrm{w} / \mathrm{w}$, and $0.6 \% \mathrm{w} / \mathrm{w}$. Each boxes was leaned and arranged on another box to allow free drainage for water collecting. The boxes has been prepared and planted with the plant material in January, to give the species enough time to establish in the new places. For both species cuttings has been used.

The monitoring apparatus includes a weather station, and a precision balance to measure the variation in boxes weight. Individual rainfall event were defined as those being separated by an inter-event dry weather time of more than $24 \mathrm{~h}$. To attain volume runoff measurements, the amount of water drained in each container was measured exactly after the end of the drainage due to the rainfall. Retention was calculated using the method described by Cipolla et al. (2016), which uses the following equation: Retention= 
(Precipitation - Runoff) / Precipitation [\%]. The water losses due to evapotranspiration (ET in $\mathrm{mm}$ /day) were evaluated measuring the difference between the daily changes in weight of the box. This has allow comparing the measured ET daily losses with those estimated using the Hargreaves (HA) and the FA054 Penman-Monteith (PM) equations. To determine LDMC , three leaf samples for each species were collected from five different individuals growing in the boxes. Healthy, fully expanded leaves from well-developed plants were selected, within 2 $\mathrm{h}$ of collection, fresh weight was measured then the leaves were dried at $50^{\circ} \mathrm{C}$ for $48 \mathrm{~h}$ and dry weight was measured. LDMC is the measure of dry leaf weight (mg) divided by fresh leaf weight (g) and it was measured at the beginning of the experiment, and after three months. To determine RWC five leaves for each species were collected and the fresh weight were determined, followed by flotation on water for up to $4 \mathrm{hr}$. The turgid weight is then recorded, and the leaves are subsequently oven-dried to a constant weight at about $85^{\circ} \mathrm{C}$. RWC is calculated by: RWC $=($ fresh weight - dry weight $) /($ turgid weight - dry weight $)$ and is defined as a percentage.

\section{RESULTS AND DISCUSSION}

The experimental activity was carried out over two periods. Period I (Dec.2014-Apr. 2015), and Period II (May-to Jun. 2015). Hydrogel was added in late autumn (10/12/2014), during the preparation of the green roofs modules, and in late spring (19/05/2015). As in the study proposed by Savi et al. (2014) a significant loss of water holding capacity of substratehydrogel blends was observed in late April and that is why hydrogel was added again on May 2015. In order to saturate the substrate, each box was dipped in water for $48 \mathrm{~h}$ and then it has been left free to drain after hydrogel was added.

Table 1. Summary of the field experiment results: date, precipitation depth ( $\mathrm{mm})$, antecedent dry weather time (ADWT, days), measured retention for Sedum and Bromus for the different concentration of hydrogel $(0 ; 0.3 ; 0.6 \%)$.

\begin{tabular}{lcllcllll}
\hline \multirow{2}{*}{ Date } & $\begin{array}{c}\text { Precipitation } \\
{[\mathrm{mm}]}\end{array}$ & $\begin{array}{c}\text { ADWT } \\
{[\text { day] }}\end{array}$ & \multicolumn{3}{c}{ Sedum retention } & \multicolumn{3}{c}{ Bromus retention } \\
& & & $0 \%$ & $0.3 \%$ & $0.6 \%$ & $0 \%$ & $0.3 \%$ & $0.6 \%$ \\
$26 / 05 / 2015$ & 8.2 & 2 & 34.6 & 78.6 & 55.9 & 11.9 & 35.8 & 56.7 \\
$14 / 06 / 2015$ & 60.6 & 13 & 46.9 & 57.6 & 61.7 & 20.3 & 58.5 & 83.9 \\
$27 / 06 / 2015$ & 12.2 & 2 & 90.2 & 84.3 & 98.0 & 85.9 & 88.1 & 95.1 \\
\hline
\end{tabular}
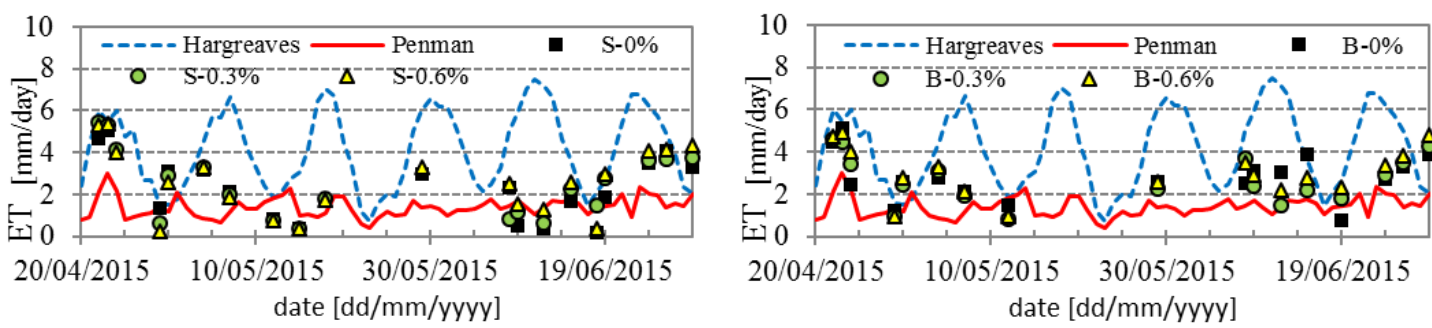

Figure 2. Indicators show the measured moisture loss due to evapotranspiration for the test boxes covered with Sedum ( $\mathrm{S}$, left) and Bromus (B, right), while the red and blue lines represent the daily moisture losses calculated with the Penman and Hargreaves and equation respectively.

The presence of hydrogel influence the hydrological balance increasing the water retention, in fact the data resulted from this research (Tab. 1) indicates that modules with higher amount of hydrogel shows significantly higher retention. The only two exceptions are the $S=3 \%$ and the $S=0 \%$ respectively in the first and third event, which showed a retention 
higher than the other configurations. In the case of Bromus species, the retention values grow together with the hydrogel concentration. The daily ET losses for each configuration are shown in the fig. 2 (left) for Sedum and in fig. 2 (right) for Bromus. The higher the hydrogel concentration the higher the daily ET losses for both species. Moreover, comparing the measured daily ET losses, with two empirical methods to calculate potential evapotranspiration (PET) proposed by HA and PM, it may be noticed that PET measure with $\mathrm{PM}$ is the most similar to measurements for both species. The presence of hydrogel has an impact on the growth of the two species. As shown in Table 2 the LDMC values for the two species show a decreasing. For both species higher is the hydrogel concentration higher is the LDMC decreasing. For Bromus the decreasing it seems to be more pronounced. LDMC has been shown to correlate negatively with potential relative growth rate; our result shows that the presence of hydrogel can help the plant growth confirming the results of Savi et al. 2014. As shown in Figure 3, the different hydrogel concentrations, and thus the greater presence of humidity in the substrate, appear to have no effect on the RWC of the two species. In Sedum, this can be due to the fact that Sedum is a CAM-type species, whereas for Bromus can be due to the fact during the days of measurements the rain satutared the boxes and there were no differences between the three hydrogel concentrations.

Table 2. Measured LDMC for Sedum and Bromus for the different concentration of hydrogel $(0 ; 0.3 ; 0.6 \%)$ at the beginning of the experiment and after 3 months

\begin{tabular}{lccclcc}
\hline Date & \multicolumn{3}{c}{ Sedum LDMC $[\mathrm{mg} / \mathrm{g}]$} & \multicolumn{3}{c}{ Bromus LDMC [mg/g] } \\
\cline { 2 - 7 } & $0 \%$ & $0.3 \%$ & $0.6 \%$ & $0 \%$ & $0.3 \%$ & $0.6 \%$ \\
\hline $15 / 01 / 2015$ & 98.5 & & & 350.24 & & \\
$15 / 04 / 2015$ & 101.17 & 79.82 & 73.97 & 292.55 & 271.85 & 255.10 \\
\hline
\end{tabular}
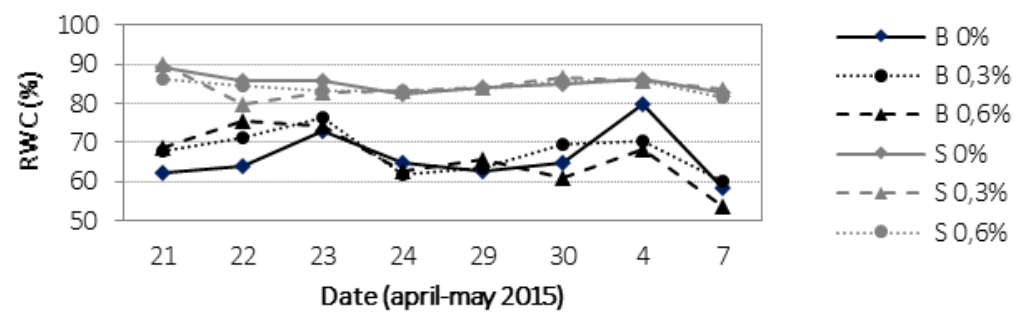

Figure 3. Measured relative water content (RWC) for Sedum and Bromus.

\section{CONCLUSIONS}

The experimental results show that even a small percentage of hydrogel can influence the hydrological balance of a green roof both in term of average retention and evapotranspiration; the presence of hydrogel can also influence the plant growth but has no effect on the species water status.

\section{Licterature cited}

Cipolla, S.S., Maglionico, M. and Stojkov, I., (2016a). Experimental Infiltration Tests on Existing Permeable Pavement Surfaces. Clean - Soil, Air, Water 44 (1), 89-95. doi:10.1002/clen.201400550

Cipolla, S.S., Maglionico, M. and Stojkov, I. (2016b). A long-term hydrological modelling of an extensive green roof by means of SWMM. Ecol. Eng. 95, 876-887. doi:10.1016/j.ecoleng.2016.07.009

Farrell, C., Ang, X.Q. and Rayner, J.P. (2013). Water-retention additives increase plant available water in green roof substrates. Ecol. Eng. 52, 112-118. doi:10.1016/j.ecoleng.2012.12.098

Gross, N., Suding, K.N.K. and Lavorel, S. (2007). Leaf dry matter content and lateral spread predict response to land use change for six subalpine grassland species. J. Veg. Sci. 18, 289-300. doi:10.1111/j.1654-1103.2007.tb02540.x Savi, T., Marin, M., Boldrin, D., Incerti, G., Andri, S. and Nardini, A. (2014). Green roofs for a drier world: Effects of hydrogel amendment on substrate and plant water status. Sci. Total Environ. 490, 467-476.

Young, T.M., Cameron, D.D. and Phoenix, G.K. (2017). Increasing green roof plant drought tolerance through substrate modification and the use of water retention gels. Urban Water J. 14(6), 551-560 